\title{
Indexicality and The Answering Machine Paradox*
}

\author{
Eliot Michaelson ${ }^{\dagger}$ and Jonathan Cohen ${ }^{\ddagger}$
}

\begin{abstract}
Answering machines and other types of recording devices present prima facie problems for traditional theories of the meaning of indexicals. The present essay explores a range of semantic and pragmatic responses to these issues. Careful attention to the difficulties posed by recordings promises to help enlighten the boundaries between semantics and pragmatics more broadly.
\end{abstract}

The invention is of great importance for telephonic purposes, as by providing a suitable apparatus in combination with a telephone communications can be received by the apparatus when the subscriber is absent, whereas upon his return he can cause the communications to be repeated by the apparatus. US Patent 661,619, for the Telegraphone - 13 November 1900

Indexicals (paradigmatically 'I', 'here', and 'now') have long served as a focal point for philosophical debates about context-sensitivity. Famously, Kaplan (1989) noted that these expressions exhibit more regularity than many other context-sensitive terms (e.g., demonstratives), and proposed a straightforward set of rules ('characters') for associating each with a semantic value, relative to a context. Thereby, he provided an intention-free formal semantics to account for indexicals.

Unfortunately, this simple and powerful picture is threatened by examples involving inscriptions and audio recordings. The best-known is the 'answering machine paradox': since there is no speaker when an answering machine is triggered, Kaplan's theory predicts that answering-machine occurrences of ' $\mathrm{I}$ ' fail to refer. Yet answering machines regularly and successfully communicate information about specific individuals.

\footnotetext{
*This paper is entirely collaborative; authors are listed in anti-alphabetical order.

$\dagger$ Department of Philosophy, University of California, Los Angeles, Box 951451, Dodd Hall 321, Los Angeles, CA 90095, eliot.michaelson@gmail.com

$\ddagger$ Department of Philosophy, University of California, San Diego, 9500 Gilman Drive, La Jolla, CA 92093-0119, joncohen@aardvark.ucsd.edu
} 
This essay explores a range of semantic and pragmatic solutions to this paradox. These proposals merit attention not only for their intrinsic interest, but also because of the larger issues they raise about the appropriate range of data for semantics and pragmatics, and about the division of explanatory labor between these components of our total theory of language.

\section{Answering Machines and the Classical View}

As Kaplan (1989. 491, note 12) observes, the apparent fact that answeringmachine produced tokens of (1) communicate something true and informative about particular individuals conflicts with the now-canonical semantics for indexicals developed there ${ }^{1}$

(1) I am not here now.

For Kaplan, the semantics of indexicals turns on the interaction of two aspects of their meaning - character and content - with the context of use (and, ultimately, with circumstances of evaluation) ${ }^{2}$ An expression's content is a mapping from circumstances of evaluation to extensions (501). (For sentences, we can think of contents as "the what-is-said in a given context" (494) - something that maps from circumstances of evaluation to truth values, which are the extensions for sentences). Kaplan's second kind of meaning, character, is described as "a meaning rule," that which is "set by linguistic conventions and, in turn, determines the content of the expression in every context," and a "function from possible contexts to contents" (505). Kaplan captures the context-sensitivity of indexicals by saying that indexicals have contextually-invariant characters that map to different contents as a function of the context: ' $I$ ' interpreted relative to a context whose agent is Barack Obama has one content, while 'I' interpreted relative to a context whose agent is David Kaplan has another.

Suppose, with Kaplan, a context $c$ can be represented by a sequence of particulars including an agent $c_{A}$, a location $c_{P}$, a time $c_{T}$, and a world $c_{W}$.

\footnotetext{
${ }^{1}$ The version of "Demonstratives" finally published in 1989 circulated widely from around 1977. Thus, despite claims to this effect by, e.g., Perry (2003 376), it is false that Kaplan had, in constructing his theory, failed to anticipate the technological possibility of answering machines, or the threats they raise to his semantics. In any case, though the behavior of answering machines makes the clash vivid, the problem arises for journal entries, inscriptions left on blackboards, notes sent on postcards, or cases (such as one Kaplan (1989. note 12) attributes to Donnellan) where sound moves very slowly; and it is hard to believe (even if it were true that he had failed to consider answering machines specifically) that Kaplan had avoided encounters with the other pieces of technology that raise the problem - e.g., the pencil. Intuitively, what unites such cases and makes them problematic for Kaplan's (otherwise successful) semantics is that the speaker who linguistically encodes the message needn't be located at the place and time at which the message token is decoded by a recipient.

${ }^{2}$ Crucially, the puzzle of the answering machine arises within Kaplan's treatment of indexicals, which constitute a subset of the occurrences of the word-forms ' $I$ ', 'now', 'here', etc. Kaplan (1989. 489-490) clearly points out that the words that interest him have both indexical and non-indexical uses, and explicitly sets the latter outside the scope of his theory. As such, (pace Vision, 1985, Smith. 1989) non-indexical occurrences are not counterexamples to that theory.
} 
Kaplan's character axioms stipulate that 'I' refers to $c_{A}$, 'here' to $c_{P}$, and 'now' to $c_{T}$; and he holds that for any "proper" context $c_{,} c_{A}$ must be located at $c_{P}$ and $c_{T}{ }^{3}$ It follows from these stipulations that (2) is a 'logical truth' within his semantics: it is true whenever tokened (509).

\section{(2) I am here now.}

And, given the usual semantics for negation, it similarly follows that (1) is a 'logical falsehood': it is false whenever tokened.

Thus, the received semantic machinery for indexicals apparently has as a trivial consequence the denial of a banal fact about natural language made manifest by ordinary 1970s consumer technology. Presumably, then, some modification of that machinery is called for. But what?

\section{Pragmatic Accounts}

Though most published discussions respond to the problem in semantic terms, a natural initial thought would be to offer a pragmatic solution.

Thus, one might supplement Kaplan's semantics with standard Gricean mechanisms to explain the actual communicative impact of answering machine uses of tokens like (1). On such a view, the answering machine recording would literally say something false, but would communicate something true, something like: the original speaker isn't at the time/place where this answering machine has been triggered. (Or, simpler still: the speaker isn't available when you're calling.)

Such extrasemantic communicated content is typically explained in terms of conversational implicature ${ }^{4}$ If so, two problems arise.

First, unlike paradigmatic conversational implicatures, answering machine recordings of (1) cannot be canceled, as indicated by the infelicity of $\left(1^{\prime}\right)$ :

(1') \# I am not here now, but I might be when you are listening to this.

The pragmatic theorist might attempt to bite this bullet, but this means giving up one of our best criteria for distinguishing semantic from pragmatic content ${ }_{5}^{5}$ Second, the envisaged pragmatic story risks being self-undermining.

\footnotetext{
${ }^{3}$ Kaplan's reasons for these stipulations are complicated; for discussion, see Michaelson (2013b).

${ }^{4}$ Pragmatic theorists might try to invoke conventional implicature instead; but that sort of Gricean content looks ill-suited to the task at hand. In particular, such content is generally taken to supplement what is said, strictly speaking - viz., to convey some further information on top of that content - rather than supplanting it.

${ }^{5}$ Perhaps a pragmatic theorist might offer an independent explanation of the infelicity $\left(1^{\prime}\right)$ by claiming that its cancellation clause (viz., its second conjunct) is either false or uninformative that it either states something false about the speaker's state at the time/place of utterance, or something trivial about the time/place of triggering. However, note that the cancellation clause of $\left(1^{\prime}\right)$ can be informative in the right circumstances - such as when the caller had previously assumed that the listener is not the sort to screen her calls. We take it that $\left(1^{\prime}\right)$ is still infelicitous even in these circumstances, which suggests that the proposed explanation of its infelicity is unsuccessful.
} 
For if answering machine uses of (1) regularly and systematically convey this extrasemantic content, as per the pragmatic proposal, it is a puzzle why that content wouldn't become conventionalized, hence semantic. That is, we worry that the current proposal that the association between (1) and the content in question is extrasemantic is potentially unstable - that, just by virtue of its prevalence and regularity, the association threatens to become semantic after all. If so, of course, then the pragmatic proposal is not, advertisements to the contrary notwithstanding, an alternative to the view that the content communicated by (1) is semantically encoded 6

In response, the pragmatic theorist might loosen her attachment to any particular pragmatic theory and claim only that, by some mechanism or other, answering machine machine uses of (1) standardly convey that the speaker isn't available right now. But it's hard to see why, if this is the content that answering machine uses of (1) convey, (1) cannot be used to convey the same thing when recorded as an outgoing message for a cellular telephone 7 One natural explanation is that what (1) means doesn't fit this new situation

The semantic accounts we explore below are aimed at making good on this suggestion.

\section{Ambiguity}

One early approach to the puzzle claims that indexicals are (not only contextsensitive, but) ambiguous - that they can refer to elements of either of two distinct contexts. Indeed, in raising the puzzle, Kaplan (1989) himself appears to endorse this suggestion 9

If the message: "I am not here now" is recorded on a telephone answering device, it is to be assumed that the time referred to by 'now' is the time of playback rather than the time of recording. Donnellan has suggested that if there were typically a significant lag between our production of speech and its audition (for example, if sound traveled very slowly), our language might contain two forms of 'now': one for the time of production, another for the time of audition... (Kaplan, 1989, 491, note 12).

The idea that emerges (and is developed by Smith (1989)) is that 'now' is lexically ambiguous: it may refer either to the time of the context of

\footnotetext{
${ }^{6}$ These considerations parallel a criticism by Devitt (1997) and Reimer (1998) against Kripke (1977), who appeals to Grice to defend the Russellian theory of definite descriptions. One might object that this line of response overpredicts semantic ambiguity - e.g., that it predicts that the interrogative form 'can you pass the salt?' has the regularly associated content do pass the salt as one of its literal semantic contents. For a reply to this objection and defense of this style of criticism, see Reimer (1998).

Thanks to lvano Caponigro for this observation.

${ }^{8}$ One piece of support for this explanation is that, to our ears at least, hearing (1) as the outgoing message for an unknown line counts as evidence that one has called a landline.

${ }^{9}$ Nonetheless, Kaplan (1989) does not incorporate the idea into his official semantics for indexicality.
} 
production/inscription $\left(c^{i}\right)$ or to that of the context of audition/tokening $\left(c^{t}\right) 1^{10}$ Perhaps, likewise, 'here' and ' $\mathrm{I}$ ' refer ambiguously to either the place/agent of $c^{i}$ or the place/agent of $c^{t}$. If so, then since there are three indexical expressions in (1) (ignoring tense), each ambiguous between two readings, there should be a total of $2^{3}=8$ possible readings for (1) ${ }^{11}$

Presumably the view would be that, while these readings collapse onto the single, standard interpretation (which Kaplan's semantics guarantees to be false relative to any proper context) when $c^{i}=c^{t}$, tokens of (1) nonetheless express truths when (because of the use of answering-machines, the slow travel of speech sounds Donnellan suggests, or whatever) $c^{i} \neq c^{t}$. How might listeners then disambiguate tokens of (1) to arrive at a unique content when $c^{i} \neq c^{t}$ ? Perhaps pragmatic constraints - e.g., the semantically guaranteed falsity of the standard interpretation - guide listeners to a specific alternative disambiguation.

While schematic, the strategy outlined looks initially promising as an answer to the puzzle. Moreover, the proposal is a conservative extension of the classical machinery: it validates the official Kaplanian semantics in the special cases where $c^{i}=c^{t}$, and incorporates a simple, localized, yet powerful extension where $c^{i} \neq c^{t}$.

However, the proposal depends on a postulated lexical ambiguity that is not supported by the evidence ${ }^{12}$ Specifically, application of a standard test involving the possibility of non-contradictory explicit cancellation under crossed readings tells against the presence of an ambiguity. To see this test in action, note that, because 'bat' is lexically ambiguous (between an animal and a piece of baseball equipment), there is a non-contradictory reading of

\footnotetext{
${ }^{10}$ Smith denies that his position amounts to an ambiguity view, since it involves associating each indexical word-form not with multiple, distinct meanings, but with a single 'metarule' - a function from speakers' intentions to ordinary characters (Smith 1989. 168). We find Smith's characterization of his view as something other than an ambiguity theory unpersuasive. For, on his view, the choice between the semantic properties of a given word form is placed under the intentional control of the speaker, and requires of that speaker that she select from a finite number of available (and possibly semantically unrelated) alternatives. In short, Smith's suggested metarules appear to be more of an implementation of the standard picture of lexical disambiguation than an alternative to it. Moreover, Smith's theory is vulnerable to the worries pressed below against ambiguity views. (However, as we will see in $\$ 6$ the idea of a meta-rule can be developed in other, genuinely non-ambiguity-theoretic, ways.)

${ }^{11}$ In note 12, Kaplan specifically mentions (and attributes to Donnellan) only the application of the ambiguity strategy to 'now' (despite having raised the puzzle about a string that also contains 'here' and 'I'). Smith (1989) endorses all eight of the readings considered here (and more) as possible disambiguations of (1).

${ }^{12}$ Unfortunately, many standard tests for lexical ambiguity are hard to apply to the cases at hand. For example, Predelli (2011) appeals to the absence of languages in which the indexicals under consideration have distinct lexical expressions as evidence against the ambiguity view. For, he argues that if these words were ambiguous, we would expect to find languages in which the supposed coincidental overlaps in lexical expression failed to obtain. However, the ambiguity theorist will respond that there is a systematic connection between the allegedly distinct disambiguations of the relevant expressions (as there is not between the disambiguations of the English 'bank'), hence that their shared linguistic expression is non-accidental, hence likely to be sustained in other natural languages. As such, this test doesn't deliver a clean verdict about the case. (We omit discussion of other ultimately indecisive tests for reasons of space.)
} 
(3) Alyosius bought a bat but Alyosius didn't buy a bat.

(namely, a reading on which its two occurrences of 'bat' receive distinct interpretations). But 'here' and 'now' fail this test: once a context is fixed, there is no available reading of (4) or (5) (treating the relevant word forms as indexicals) that avoids contradiction 13

(4) Alyosius is here but Alyosius is not here.

(5) Alyosius is present now but Alyosius is not present now.

There is a further problem for the ambiguity view: it is not clear how, if target instances of (1) are ambiguous between eight interpretations, listeners manage to single out one of them. As suggested, in answering machine cases one or more candidate disambiguations (e.g., the canonical interpretation that the agent of $c^{i}$ is not located at the time of $c^{i}$ at the time of $c^{i}$ ) might be ruled out by their obvious falsity. But it's unclear what post-semantic constraints would tilt the balance uniquely in the favor of one of the rest (given that, ex hypothesi, semantic constraints leave alternatives open) - and there is no evidence that hearers take such instances of (1) to be ambiguous between multiple candidates.

\section{Modified Character}

Sidelle (1991) and Cohen (2013) offer a solution to the paradox that eschews ambiguity, and instead depends on a modest modification of Kaplan's semantics. Sidelle and Cohen again distinguish between the context of production/inscription $\left(c^{i}\right)$ and the context of audition/tokening $\left(c^{t}\right)$, and suggest that 'here' and 'now' refer to the place and time $c^{t}$, rather than (per Kaplan) the place and time of $c^{i}$ This constitutes a conservative departure from Kaplan's semantics, since whenever $c^{i}=c^{t}$ (e.g., in face to face communication) it returns the same result. However, when (1) is used on an answering machine, this view predicts that the sentence is true iff the speaker at the original context is not present when and where the answering machine is triggered - thus matching standard intuitions.

Interestingly, though he initially proposes this view, Sidelle (1991) abandons the modified character view by the end of the paper (in favor of a doxastic control theory; cf. 85 in the face of apparent counterexamples involving lost inscriptions:

\footnotetext{
${ }^{13}$ We must fix a context because there is a true/non-contradictory reading of (5) where Alyosius leaves in the middle of the utterance.

The parenthetical restriction to indexical uses is needed because (4) and (5) have noncontradictory readings where at least one instance of the relevant forms is read as a demonstrative rather than an indexical (cf. note2).

${ }^{14}$ Cohen holds that 'I' is unlike 'here' and 'now' in that the former picks out a parameter of the context of production/inscription; Sidelle doesn't raise this issue explicitly, but refrains from applying the sort of modification he envisions for 'here' and 'now' to ' $I$ ', which suggests that he takes a similar view.
} 
[C]onsider an 'I am at the store' message which gets lost and discovered some years later. Surely no utterance is being made when the note is discovered and read (Sidelle, 1991, 357).

But Cohen (2013) argues that Sidelle was overhasty in giving up his theory. Cohen concurs that no utterance is made in the case at hand, and that the author had no intention of informing a reader, years later, that she is at the store when the note is read. However, he notes that these claims are consistent with holding that the inscribed sentence has a distinct meaning relative to the later circumstances, and is false when evaluated relative to those circumstances (Cohen, 2013, 7-8) ${ }^{15}$ If so, then such cases are not, after all, inconsistent with the modified character view.

Despite its merits, Michaelson (2013b, 17-18) points out that the modified character view faces challenges from other kinds of inscriptions, such as postcards. Consider, for example, a postcard on which is inscribed only:

(5) It's beautiful here now.

Modified character views seem to predict, counterintuitively, that this use of (5) is true iff it is beautiful at the time and place where the postcard is read, not where it is inscribed.

While accepting that this is an important challenge, Cohen (2013, 24, note 32) proposes on behalf of the modified character view that the problematic occurrences of 'here' and 'now' might be treated as either bound variables or demonstratives. If so, then the cases at hand would fall outside the scope of the semantics for indexicals, so would not amount to counterexamples to the theory (cf. note 2). The good news about this proposal is that there is abundant evidence of the existence of bound and demonstrative uses of these forms, and that their semantic properties differ from those of indexical uses of the same forms. The bad news is that it is difficult to assess the proposal, since there are no uncontroversial criteria for distinguishing bound variable and demonstrative uses from indexical uses of these word forms. Hence, this remains an outstanding challenge to the modified character view ${ }^{16}$

\section{Doxastic Control}

Another response to the paradox - a family of views we call doxastic control theories - involves the idea that the speaker's intentions or audiences' expectations, rather than fixed linguistic conventions enshrined in character rules, determine indexical reference 17

\footnotetext{
${ }^{15}$ One might resist this suggestion by insisting that, pace Kaplan, semantics properly attaches to utterances rather than sentences-in-contexts. For elaboration of this distinction, and an attempt to use it to bypass the answering machine paradox, see Stevens (2009). For criticism, see Cohen (2013); Michaelson (2013b).

${ }^{10}$ For further discussion, see Michaelson 2013b a.

${ }^{17}$ The earliest source for the doxastic control theory we know of is Sidelle 1991. 537) who, after giving up the modified character view he proposed in that paper, goes on to suggest
} 


\subsection{Speaker Control}

Perhaps the most prominent doxastic control theory, due to Predelli (1996. 1998a b. 2002, 2005), holds that intentions of speakers fix the context with respect to which the indexicals in their utterances are to be interpreted, thereby fixing their referents as well. Specifically, Predelli proposes that a token encoded/inscribed in context $c^{i}$ should be evaluated with respect to the unique context $c^{i n t}$ that the agent of $c^{i}$ intends for the evaluation of her message. Call this the speaker control view. In ordinary, face to face communicative settings, $c^{i}$ will be identical to $c^{i n t}$, so the speaker control view will collapse onto Kaplan's semantics for standard cases. But Predelli identifies three kinds of cases where, he claims, $c^{i} \neq c^{i n t}$, and argues that the speaker control view is preferable in such cases 18

The first is the answering machine case. As we have seen, Kaplan's semantics makes counterintuitive predictions about non-screening answeringmachine-produced uses of (1). Predelli's semantics, in contrast, predicts that such a token of (1) is true just in case the agent of $c^{\text {int }}$ is not located at the location/time of $c^{i n t}$. (Predelli assumes that the context $c^{\text {int }}$ that the agent of $c^{i}$ intends contains herself as its agent, the location of playback as its location, and the time of playback as its time.) And Predelli thinks this is the correct truth-condition for the token (but see below).

Predelli's second motivation trades on intuitions about how content shifts when unexpected vicissitudes befall inscriptions:

Consider the anecdote of Jones, who expects his wife to come home at six, and writes 'I am not here now' at four, with the intention of informing Mrs. Jones that he is away from home at six - or, if you prefer, imagine that he records 'I am not here now' on a tape, expecting his wife to activate the tape-recorder upon her arrival. However, Jones's wife is late, and she only reads the message (or turns on the tape-recorder) at ten. Clearly the vicissitudes of Mrs. Jones do not affect the content of Jones's message. Intuitively, such

(noncommittally) two possible alternative responses, which turn out to be the speaker control and audience control versions of doxastic control views.

18 Though we focus on Predelli's version of the speaker control view, there are two nearby relatives worth mentioning.

A first, advocated by Voltolini 2006); Recanati 2000, holds that a token indexical encoded in $c^{i}$ should be evaluated with respect to the unique context $c^{p_{i}}$ that, according to the pretense in force in $c^{i}$, is relevant for its evaluation. However, Voltolini (2006) emphasizes that what pretense is in force in a context is fixed by a combination of the speaker's intentions and conventional constraints not under her doxastic control; hence, this view is not a pure speaker control theory. (For what it is worth, we are unclear just what makes it the case that one pretense rather than another is in force in $c^{i}$, or how such a pretense singles out one unique context for the interpretation of indexicals; therefore, we have difficulty understanding the concrete predictions of this view.)

Another neighboring view comes from Recanati (2001); Krasner (2006); Mount (2008), who treat the indexicals in question as complex demonstratives ('this person', 'this place', 'this time'). This view will fall under the doxastic control heading given the standard (but detachable) assumption that demonstratives get their reference as a function of the doxastic states of their users.

Though we'll ignore these views in what follows for reasons of space, several of our general criticisms of doxastic control views $(\$ 5.3$ apply to them. 
content is to be established with respect to the time of intended decoding, and not with respect to the time when decoding actually took place (Predelli, 1998a, 110) 19

The intuition Predelli cites is incompatible with Kaplan's semantics: the latter predicts that Jones's token of 'now' refers to the time of $c^{i}$ - here 4:00, rather than either 6:00 or 10:00. In contrast, Predelli's case stipulates that the agent of $c^{i}$ (Mr. Jones) has a determinate intention about the context $c^{i n t}$ in which the note/recording is decoded by Mrs. Jones; and since the speaker control view holds that the note's token of 'now' picks out the time of $c^{i n t}$, the theory matches Predelli's intuition.

Predelli's final motivation concerns sentences in the so-called "historical present," such as:

(6) Napoleon brings his troops to the river; now he rests, and mounts his horse (cf. Smith (1989), Romdenh-Romluc (2006, 261)).

Again, this case apparently threatens Kaplan's semantics, since if we take the occurrence of 'now' in (6) to pick out the time of the context of inscription (e.g., a time in 2013), (6) expresses a falsehood. In contrast, the speaker control view predicts that the occurrence of 'now' in (6) picks out the time parameter of $c^{i n t}$, i.e., the context intended by the agent of $c^{i}$; hence it predicts that a contemporary utterance of (6) in a context $c^{i}$ is true just in case Napoleon rests and mounts his horse at the time of the unique context $c^{i n t}$ that the agent of $c^{i}$ intends for the evaluation of her utterance.

Unfortunately, these motivations are unconvincing. To begin, while it is true that the speaker control view better handles the answering machine case than does Kaplan's semantics, there are several alternatives that can boast this advantage, and Predelli says nothing to rule them out. Second, the unexpected vicissitudes case involving Jones succeeds only to the extent we share Predelli's intuition that 'now' in the note (semantically) refers to the time of intended interpretation (6:00). But (to rely on a familiar distinction from Kripke, 1977), while 6:00 is plausibly the token's speaker referent - that particular the speaker has a specific intention to pick out by his use of the token - it is far less clear that 6:00 is the token's semantic referent - that particular picked out by the expression given the public conventions governing the language, together with facts about the utterance and the way the world is ${ }^{20}$ Indeed, since the case crucially builds in incomplete knowledge, it is predictable that intuitions about what its participants intend to communicate by their words, and on the basis of which they coordinate their action, fail to reveal the words' semantic referents. Finally, the historical present use of 'now' in (6) is arguably better understood not as an indexical, but as a bound variable (cf. Corazza, 2004) - here bound

\footnotetext{
19 Vision (1985, 199) and Sidelle (1991) offer earlier versions of this case.

${ }^{20}$ It may be interesting to notice the evolution in the responses of at least one other commentator: Perry initially accepted Predelli's intuitions (Perry, 2003) but later disclaimed them (Perry, 2006).
} 
by the time of, or following, the event mentioned in the immediately preceding discourse fragment (viz., that of Napoleon's bringing his horse to the river) ${ }^{21}$

\subsection{Audience Control}

Romdenh-Romluc (2002, 2006) proposes an audience-centric counterpart to Predelli's speaker-centric doxastic control view. Specifically, she proposes that the context relative to which indexicals should be semantically interpreted is that context recognized by a competent and attentive audience making use of cues she would reasonably take the speaker to be exploiting (RomdenhRomluc, 2006, 274). Crucially, Romdenh-Romluc adverts to an idealized audience because she recognizes that actual audiences can be misinformed, confused, incompetent, or ignorant about the context with respect to which indexicals should be evaluated; and she wants to say that, in such cases, these audiences misidentify the content of the utterances they hear (RomdenhRomluc, 2006, 274).

Romdenh-Romluc motivates her view largely through the cases Predelli mentions: since (in successful communication, anyway) competent audiences typically recognize and interpret indexicals relative to the very same contexts intended by speakers, audience- and speaker control views generally coincide in their predictions, and therefore the former inherit the advantages/disadvantages of the latter regarding such cases (see \$5.1). However, Romdenh-Romluc offers one further case, which she takes to favor her view over a speaker control view, in which an imagined character, Simeon, mistakes a day on which he is to read the news on television for a day on which he is to recount history on television:

He goes on air, and thinking of the Norman Conquest says,

... Now the French are invading England!

Simeon intends his utterance to be interpreted with respect to 1066.

But everyone listening to his news programme identifies 2003 as the context of interpretation, thus taking 'now' to refer to 2003. They are subsequently horrified as they think that France has declared war on England (Romdenh-Romluc, 2006, 266).

\footnotetext{
${ }^{21}$ Yet a third view of the historical present examples, urged by Voltolini (2006), treats the latter in terms of a shared pretense to advert to a distinct context for the evaluation of indexicals (see note 18 above); as remarked, Voltolini thinks such pretense is only partially under the doxastic control of the speaker, so on this view, the case doesn't motivate the speaker control view as Predelli maintains.

Plausibly, many of the same issues and theoretical options apply to occurrences of 'now', 'here', 'tomorrow', etc. in so-called free indirect discourse, such as occurs in

(5') Tomorrow was Monday, Monday and the beginning of another school week! (Lawrence, Women in Love, p. 185, London: Heinemann 1971).

(For discussion, see Schlenker 2004).)
} 
Romdenh-Romluc's intuition is that, in making his utterance in $c^{i}$, Simeon says something false about 2003 - i.e., a time recognized by the competent audience of $c^{i}$, rather than (as Predelli's speaker control view seems to predict) something true about 1066.

Unfortunately, the audience control view is underspecified, undermotivated, and subject to counterexamples.

It is underspecified because - even conceding that the notions of competence, attentiveness, and what it is reasonable for a speaker to exploit as a cue can be explained satisfactorily - it's unobvious that there is one unique context that would be identified by the idealized audience, or how the process of context-identification by such an idealized audience would work. This makes it hard to know just what the audience control theory predicts about cases 22

The view is undermotivated because, on the one hand, as urged in \$5.1. the cases Romdenh-Romluc follows Predelli in endorsing as motivations are unconvincing. And on the other hand, the single new motivation RomdenhRomluc adds (that involving Simeon, the confused broadcaster) is, contrary to her intended lesson, agnostic between speaker control and audience control views. For if idealization is a legitimate strategy for avoiding cases in which actual audiences fail to identify the semantically relevant context as she proposes ${ }^{23}$ Predelli should be allowed to invoke an analogous idealization to insulate his view from problems resulting from the errors of actual/nonidealized speakers (e.g., Simeon).

Romdenh-Romluc's view is also subject to counterexamples. Thus, Weatherson (2002) offers cases in which (idealized) audiences reasonably identify what is intuitively the wrong context for interpretation, and so are misled into consideration of the wrong content. Weatherson imagines playing a trick on a colleague whose full departmental mailbox suggests that he hasn't checked his mail in several days. On a day when a faculty meeting will take place, we leave an undated note in his mailbox reading

(7) There is a faculty meeting today.

We follow Weatherson in thinking that this note says something true about the day on which we leave it in the colleague's mailbox. However, when the colleague retrieves the note on that day, he may - reasonably but wrongly identify an earlier day as part of the context relative to which to interpret the note's occurrence of 'today'. Relative to the context identified by the competent audience, the note says something entirely different - here, something false about an earlier day. Such cases show that competent audiences can identify

\footnotetext{
${ }^{22}$ As remarked above (fn. 15 , some have taken the relevant object of semantic analysis to be utterances, rather than sentences-in-contexts. Though neither explicitly acknowledges this, Predelli and Romdenh-Romluc must fall in the utterance-camp as well: otherwise, it is unclear how the contexts they take to be relevant to semantic evaluation (the speaker's intended context, or the context the listener takes to be relevant) will be well-defined relative to sentence-tokens.

${ }^{23}$ See below for doubts about the antecedent of this conditional.
} 
the wrong context for the interpretation of indexicals, contrary to the audience control view 24

Proponents of the audience control view might reply that the idealization built into the account precludes the kinds of ignorance crucially involved in such attempted counterexamples. Thus, even if I or my colleague would misidentify the context controlling the interpretation of the relevant instances of (7), the theory has it that it that the content-constitutive context is that identified by idealized audiences - audiences of whom we require "competence" in a sense incompatible with making the context-identification mistakes on which the proffered counterexamples turn.

But this reply avoids the troublesome cases only by the introduction of a label ('competence', 'idealization'). The proposal comes with no account of what information must be available for an audience to count as sufficiently competent or idealized; and, given that there are so many ways in which actual audiences can be misled about contexts, it's hard to see that there could be such an account. Of course, we might stipulate that competent/ideal audiences must, by definition, have whatever information it takes to identify the unique context that determines the semantic values of the indexical expressions they hear. But since the audience control view was offered as a theory of what that semantically relevant context was supposed to be, we cannot build into the view an appeal to such knowledge without giving up the stated aim of the proposal.

\subsection{Indexicality and Doxastic Control: General Worries}

A frequently voiced complaint against speaker control views - the so-called Humpty Dumpty problem (Corazza et al. (2002, 9); Romdenh-Romluc (2006, 264); Cohen (2013, 11)) - is that they over-predict semantic variability. The worry is that, if the content-determinative context, hence the content, of a token indexical expression is fixed by the intentions of its producer, then such expressions could vary wildly in content merely by the speaker's formation of a heterodox intention. But this prediction appears false: there is just no intention by whose adoption you can make the token of ' $I$ ' in your utterance of (1) have Josef Stalin as its content (unless you are Josef Stalin). Likewise, mutatis mutandis, for 'here' and 'now' 25

\footnotetext{
${ }^{24}$ Weatherson also provides examples in which the author of a message says something false, but misleads the competent audience into interpreting the message with respect to a context so that its content is true. Cohen (2013) discusses further examples in which a competent audience fails to identify any sufficiently determinate context for the interpretation of indexicals.

${ }^{25}$ In defending his view, Predelli (2002. 315) insists that speaker intentions fix the contentdeterminative context (hence content) for indexicals, and proposes to explain away the inclination to believe otherwise in pragmatic terms. Specifically, he proposes that the the intuitions apparently telling against the intended context view reflect the realization that, without an unusual informational background, audiences won't be in a position to recover the intended referents of the indexicals, so won't be able to put what Predelli insists are the semantic contents of indexicalcontaining strings to epistemic use.
} 
The Humpty Dumpty problem arises for the speaker control view when the speaker intends the wrong context as being content-determining for the token indexicals she utters. However, analogous (if less widely noted) problems arise in cases where the speaker intends no context to be content-determining. Thus, for example, it is hard to imagine that the shipwrecked sailor who inscribes (8) on a message in a bottle intends any determinate context to govern the interpretation of its indexicals. Similarly, there are cases in which the speaker/producer intends more than one context to be content-determining, such as the billboard advertisement for apartments that contains an inscription of (9), placed next to a road prone to traffic congestion (cf. Egan. 2009):

(8) I am now stranded on a small island somewhere in the Pacific.

(9) If you lived here, you would be home now.

Indeed, similar concerns apply to audience control theories, as shown by the counterexamples to those theories discussed in $\$ 5.2$ Those counterexamples show that the contexts singled out for interpretive relevance by the doxastic states of (competent, attentive) communicative audiences come apart from the semantically content-determining contexts for indexicals. This can happen because the doxastic states of audiences - no less than speakers can single out the wrong context, no context, or more than one context (cf. Cohen, 2013. 15).

In short, the Humpty Dumpty problem appears to be more general than has been appreciated: the content of indexicals - a fortiori, the contentdetermining context for indexicals - cannot be fixed by the doxastic states of any non-omniscient thinker ${ }^{26}$ If so, no doxastic control theory can succeed.

\section{Metarules}

Lastly, we turn to a class of views that associates indexicals not with simple, context-insensitive rules of reference, but with context-sensitive 'metarules'. The basic idea is that some element of the context serves to associate a use of an indexical with an 'ordinary' character - which, in turn, maps that use to a value. Smith (1989) suggests an early version of this strategy (cf. note 10) on which speakers' intentions are the contextual element mapping uses of indexicals to ordinary characters; given this choice, his metarule account and those of a simpler ambiguity theory coincide in their predictions. Recently, however, Corazza et al. (2002); Gorvett (2005) and Michaelson (2013b) have proposed accepting the apparatus of metarules while rejecting Smith's

\footnotetext{
But this defense is unconvincing. After all, even in a context in which we stipulate that you know all about my delusions, and so are in a position to recover (/use) my heterodox intention that my token of ' $\mathrm{I}$ ' refer to Stalin, it remains false that Stalin is any part of the content I express by uttering (1).

${ }^{26}$ As we remarked in discussing the audience control view, though one might hope to save doxastic control from these problems by idealizing away from departures from omniscience, doing so means giving up on the aspiration to provide an informative theory of the target phenomena.
} 
intention-dependent implementation of it. They suggest that the metarules should be sensitive not to speakers' intentions, but to conventions (Corazza et al.) or communicative channel types (Michaelson). And they argue that the resulting metarule strategies can avoid Humpty Dumpty problems while accurately accounting for the answering machine paradox.

\subsection{Conventional Metarules}

Corazza et al. (2002); Gorvett (2005) offer a somewhat unconventional metarule account. Rather than shifting the character associated with a particular indexical at a context, they allow what counts as the agent, place, or time to vary between contexts. Thus, while ' $\mathrm{I}$ ' always refers to the agent, agents are allowed to be authors of recordings at answering-machine contexts. Corazza et al. attribute this variation to conventions governing the use of indexicals at certain sorts of contexts 27

Unfortunately, beyond saying that they will not countenance appeals to speakers' intentions in determining indexical reference, Corazza et al. offer little about the specifics of the conventions to which they appeal; this makes the overall view difficult to evaluate. However, even in its schematic form, the view suffers from several problems. First, it is unclear what determines which convention is in effect at a context. Corazza et al. treat this as a property of the context itself, but without further explanation it is difficult to see what about a context might determine this (if not speakers' intentions). Second, it is unclear that the conventions that Corazza et al. have in mind are specific enough to determine reference in cases like pointings at maps ${ }^{28}$ After all, one can point, in a single context, either to a point on the surface of the Earth or a point several thousand feet above the Earth with the very same utterance and gesture. Without appealing to something like the speaker's intentions, it is difficult to see what might pull apart these pointings - hence the conventions in effect. (For related worries, see Quine (1960).) Third, Corazza et al.'s view once more fails to rule out non-contradictory readings of (2): they fail to specify why the conventions operative at a context might not shift mid-utterance.

\footnotetext{
${ }^{27}$ Corazza et al. deny that theirs is a metarule view (14), given that they attribute to indexicals only unitary characters. We are unconvinced on this score.

It is true that, because they take the relevant conventions to affect what individuals satisfy the roles they associate with characters, but not the characters themselves, Corazza et al. (2002); Gorvett 2005) can simultaneously hold that (i) characters are intercontextually stable (e.g. ' $\mathrm{T}$ ' refers to the agent) and that (ii) indexical reference is intercontextually varying. But this distinguishes their view from metarule approaches in a merely notational way. After all, any view in the vicinity will have to distinguish between two aspects of character: a functional aspect (' $x$ ' refers to the $\psi$ ) and a metaphysical aspect (to be the $\psi$ is to be the such-and-such). Corazza et. al. push contextual variation into the metaphysical aspect of character, thereby decreasing the number of functional characters. The price, unsurprisingly, is a plethora of metaphysical conventions, knowledge of which is required for linguistic competence. The account therefore trades functional for metaphysical complexity. We see no reason to favor one of these over the other.

${ }^{28}$ Corazza et al. (2002. 14) explicitly count such demonstrative uses of indexicals as just another conventional type of use to which indexicals can be put, and to which they intend their view to apply straightforwardly.
} 
In short, while there may be a plausible conventionalist metarule theory for indexicals, we don't see that Corazza et al. (2002); Gorvett (2005) have provided one.

\subsection{Channel-Dependent Metarules}

Michaelson (2013b) proposes a metarule view on which character is sensitive to the type of communicative channel employed. He suggests that voiced utterances constitute one channel type, whereas answering machines, postcards, video wills, etc. each constitute another. And he proposes that the character rules governing indexicals depend, systematically, on the type of channel employed. Thus, in voiced utterances, 'I' refers to the speaker, 'here' to the location of production, and 'now' to the time of production. On postcards, however, 'I' refers to the author, while 'here' and 'now' remain unchanged. And on answering machines, ' $\mathrm{I}$ ' refers to the owner of the line, 'here' to the location of tokening, and 'now' to the time of tokening ${ }^{29}$

Unlike Smith's original metarule view, Michaelson's account avoids the problems facing ambiguity views. It predicts a non-contradictory reading of (4) and (5) only in the odd instance where the first clause of the sentence is voiced by Alyosius, and the second part produced by an answering machine once Alyosius has stepped out of the room. Despite the strangeness of the case, this prediction seems correct. Moreover, unlike the view of Corazza et al. (2002); Gorvett (2005), Michaelson's view does not depend on unspecified features of the context (or doxastic states) to decide between alternative entries in a given metarule 30

A remaining concern about Michaelson's metarule view is that (like the view we attributed to Smith in note 10), it ends up simply listing the character rules to be associated with each communicative channel type - in effect, that the proposal amounts to an unexplanatory list, rather than a theory. Michaelson (2013b) attempts to allay this worry by claiming that the nonstandard characters to which he appeals are solutions to the sorts of repeated coordination problems that arise in the wake of new communicative technologies. If so, he claims, the reference rules associated with each communicative channel can be fruitfully understood as conventionalized (in the sense of Lewis, (1969). So far, however, this idea has remained schematic: Michaelson has yet to explain in detail why the specific conventions at issue should have arisen in response to particular background conditions that obtained.

\footnotetext{
${ }^{29}$ As Michaelson 2013b. 7, note 6) notes, 'ownership' is probably not quite the right notion here. $\mathrm{He}$ actually needs something more like 'effective' or 'de facto' ownership - so as to account for employees' answering machines (presumably owned by their employer) and similar cases.

${ }^{30}$ Dodd and Sweeney (2010) develop a theory that, like that of Michaelson (2013b), posits that technological advances allow the reference of 'here' and 'now' to shift between the place/time of production and the place/time of tokening in certain sorts of contexts. However, since they also claim that it is the speaker's prerogative to decide whether or not reference should shift in these contexts, their view is not a pure channel type-dependence view like Michaelson's. Best we can tell, their view amounts to a restricted version of speaker-oriented doxastic control view.
} 


\section{Conclusion}

The answering machine paradox and related cases constitute a constrained, yet powerful, challenge to classical views about indexicality. Although several resolutions have been proposed, none is free from controversy. This suggests that disputes over the solution to the paradox, and the lessons it holds for the semantics and pragmatics of natural language context-sensitivity more generally, are likely to continue for the foreseeable future ${ }^{31}$

\section{References}

Cohen, J. (2013). Indexicality and the the puzzle of the answering machine. The Journal of Philosophy. forthcoming.

Corazza, E. (2004). On the alleged ambiguity of 'now' and 'here'. Synthese, 132(2), 289-313.

Corazza, E., Fish, W., and Gorvett, J. (2002). Who is I? Philosophical Studies, 107, $1-21$.

Devitt, M. (1997). Meanings and psychology. Noûs, 31, 115-131.

Dodd, D. and Sweeney, P. (2010). Indexicals and utterance production. Philosophical Studies, 150, 331-348. 10.1007/s11098-009-9416-4.

Egan, A. (2009). Billboards, bombs, and shotgun weddings. Synthese, 166, 251279.

Gorvett, J. (2005). Back through the looking glass: On the relationships between intentions and indexicals. Philosophical Studies, 124, 295-312.

Kaplan, D. (1989). Demonstratives: An essay on the semantics, logic, metaphysics, and epistemology of demonstratives and other indexicals. In J. Almog, J. Perry, and H. Wettstein, editors, Themes From Kaplan, chapter 17, pages 481-563. Oxford University Press, New York. Originally circulated as a mimeograph from the Department of Philosophy, UCLA.

Krasner, D. A. (2006). Smith on indexicals. Synthese, 153, 49-67.

Kripke, S. (1977). Speaker reference and semantic reference. In P. A. French, T. E. Uehling, and H. K. Wettstein, editors, Contemporary Perspectives in the Philosophy of Language, pages 6-27. University of Minnesota Press, Minneapolis. Reprinted in Martinich (1990).

Lewis, D. (1969). Convention. Harvard University Press, Cambridge, Massachusetts.

\footnotetext{
${ }^{31}$ Thanks to Matthew Babb, Ivano Caponigro, Nat Hansen, Alex Radulescu, and Indrek Reiland for valuable discussion of these matters.
} 
Martinich, A. P. (1990). The Philosophy of Language, second edition. Oxford University Press, New York.

Michaelson, E. (2013a). Answering machine problems. Ms., UCLA, in preparation.

Michaelson, E. (2013b). Shifty characters. Philosophical Studies. forthcoming.

Mount, A. (2008). The impurity of "pure" indexicals. Philosophical Studies, 138, 193-209.

Perry, J. (2003). Predelli's threatening note: contexts, utterances, and tokens in the philosophy of language. Journal of Pragmatics, 35(3), 373-387.

Perry, J. (2006). Using indexicals. In Blackwell Guide to the Philosophy of Language, pages 314-334. Blackwell, Malden, Massachusetts.

Predelli, S. (1996). Never put off until tomorrow what you can do today. Analysis, 56, 85-91.

Predelli, S. (1998a). I am not here now. Analysis, 58(2), 107-115.

Predelli, S. (1998b). Utterance, interpretation and the logic of indexicals. Mind and Language, 13, 400-414.

Predelli, S. (2002). Intentions, indexicals, and communication. Analysis, 62, 310-316.

Predelli, S. (2005). Contexts: Meaning, truth and the use of language. Oxford University Press, Oxford.

Predelli, S. (2011). I am still not here now. Erkenntnis, 74, 289-303.

Quine, W. V. O. (1960). Word and Object. MIT Press, Cambridge, Massachusetts.

Recanati, F. (2000). Oratio Obliqua, Oratio Recta: An Essay on Metarepresentation. MIT Press, Cambridge, Massachusetts.

Recanati, F. (2001). Are 'here' and 'now' indexicals? Texte, 127/8.

Reimer, M. (1998). Donnellan's distinction/Kripke's test. Analysis, 58, 89-100.

Romdenh-Romluc, K. (2002). Now the French are invading England! Analysis, 62(1).

Romdenh-Romluc, K. (2006). I. Philosophical Studies, 128(2).

Schlenker, P. (2004). Context of Thought and Context of Utterance: A Note on Free Indirect Discourse and the Historical Present. Mind \& Language, 19, 279-304.

Sidelle, A. (1991). The answering machine paradox. Canadian Journal of Philosophy, 21, 525-539. 
Smith, Q. (1989). The multiple uses of indexicals. Synthese, 78, 167-191.

Stevens, G. (2009). Utterance at a distance. Philosophical Studies, 143(2), 213-221.

Vision, G. (1985). I am here now. Analysis, 45(4), 198-199.

Voltolini, A. (2006). Fiction as a base of interpretation contexts. Synthese, 153(1).

Weatherson, B. (2002). Misleading indexicals. Analysis, 62(4), 308-310. 